\title{
PERFPRMANCE ANALYSIS ON POWER FLOW OF A THREE-FEEDER/MULTI-BUS DISTRIBUTION SYSTEM USING GUPQC
}

\author{
Avanish Tripathi ${ }^{1}$, Dr. Imran ${ }^{2}$ \\ ${ }^{1}$ M.Tech.(Power Systems) Scholar, Electrical Engineering department, Azad Institute of Engineering \& \\ Technology Lucknow, India \\ ${ }^{2}$ Assistant Professor, Electrical Engineering department, Azad Institute of Engineering \& Technology \\ Lucknow, India \\ 1Email-avanishtripathi03@gmail.com 르Email-pe.imran@gmail.com
}

\begin{abstract}
Power flow in any distribution system either it is multi bus or three feeder explain by a Generalized Unified Power Quality Conditioner i.e. GUPQC .On the one side that is DC side is connected with the common DC link capacitor which is also coupled consecutively through 3 voltage source converters. This is the simple block realization of GUPQC. In this multi feeder is explained where one feeder is controlled by parallel compensator and next two feeder is controlled through proposed series compensator. This technique i.e. GUPQC make the feeder distribution free from harmonic and voltage current compensation etc randomly. Also it can improve the quality of supply power given to one to another consumers. Vast and huge study of Simultaion is helped to how MATLAB/SIMULINK is used for making this type of GUPQC. Disrupted Voltage, current and power quality issues can be easily improved in this technique.
\end{abstract}

Keywords: Generalized Unified Power Quality Conditioner, Disrupted Voltage, current and power quality, three feeder/multi-bus distribution system.

\section{INTRODUCTION}

In this day and age, there's decent significance of current since it is the most prominent type of vitality and everybody are greatly wishing on it. While not give of power life can't be genuine. At a comparable time, the standard and constancy of the electrical power prepared are furthermore significant for the efficient working of the top client instrumentality.

In light of the idea and utilizations of the adaptable AC transmission frameworks (Certainties), devices in transmission line the idea of the IPFC and furthermore the GUPFC $[4,5]$ is reached out to the multi-transport/multi-feeder appropriation frameworks. On a comparative lines, expanded adaptation of the line IPFC referred to as-as AN (IUPQC) comprising of 2 VSCs, one inside the shunt to control the bus bar (line) voltage of the one feeder in dispersion framework and the other in succession (arrangement) to direct the voltage over a fragile heap of the contrary feeder, was composed in . A multi-converter Unified Power quality conditioner (MC-UPQC) having 3 VSCs associated sequentially through a standard.

DC-interface capacitance was accounted for in to finish each the present and voltage blemishes in a single feeder and furthermore the voltage flaws inside the substitute feeder. An all-encompassing adaptation of line GUPFC is arranged in [8] for PQ improvement of a multi-feeder dispersion framework known as, GUPQC that was finished by 3 VSCs associated sequentially by a standard DC- 
connect capacitance on the DC angle. By coupling 3 VSCs in sequential setups the GUPQC is working with extra adaptability and license the dynamic capacity to current from one VSC to the inverse to support PQ of 3-feeder appropriation framework. To benefit from the trading of intensity between the feeders, one among the VSCs inside the GUPQC framework was associated in shunt to a feeder through a coupling electrical gadget and furthermore the elective 2 VSCs, each nonparallel with a feeder, are associated with the contrary 2 feeders through arrangement infusion transformers. By this alliance, the arranged GUPQC can simultaneously repaying voltage and current blemishes in multi-bus/3-feeder DS. Other than that, the office is moved from one feeder to elective feeders to finish voltage and current quality issues of the framework.

This blessing work has tended to the office stream examination and pay execution of the GUPQC associated with a multi-transport/3-feeder dispersion framework bolstered the arranged new controller system for series compensators.

\subsection{Power Quality and Problems}

Power Quality (PQ) connected problems are of most concern these days. The perfect power provides voltage would maintain a gentle magnitude and a curving wave with none interruptions. Any phenomena which will alter this ideal state of affairs are classified as a disturbance. The growing quantity of power natural philosophy primarily based equipment has had a profound impact on the standard of electrical power provide. The vast use of electrical and electronic equipment's, like data technology equipment's, power natural philosophy like programmable logic controllers (PLC), Adjustable speed drives (ASD) and energy-efficient lighting cause harmonics within the network voltages. what are more, typical masses like giant arc-furnaces and fastening machines causes voltage fluctuation, voltage imbalance and flicker.These masses are at the same time the most important causes and also the major victims of power quality issues in conjunction with advanced technology.Association of the worldwide economy has developed towards proliferation and also the gain margins of the numerous campaign tend to decline. The overstated sensitivity of the massive majority of processes (industrial and residential) to PQ issues turns the delivery of electrical power with the quality become a major issue for the fight in each sector. Once a disturbance occurs, fiscal losses may be occured with the evolve loss of productivity and fight. Though several efforts are hold by utilities, some shoppers need the level of PQ beyond the extent provided by trendy electrical networks. This means that some measures should be taken so as to realize higher levels of Power Quality. it's wont to outline varied sorts of disturbances to the traditional facility voltage. a spread of disturbances like harmonics, transients, outages, faults, sags, swells, dips, and flicker is related to the term "Power Quality". Varied sorts of disturbances are outlined below:

\section{PREVIOUS WORK}

Power quality might be arranged into 3 classes that's, voltage stability, coherence of giving power and voltage supported this grouping, numerous examples of intensity quality level definitions were displayed by ToshifiimiIseet al.

Arindam Ghosh et al. Extensive audit of repaying kind custom power devices, issues with power quality, the study of intensity quality issues, norms and records arranged by totally various offices and various ways to deal with upgrade power quality every once in a while. 
Juan W. Dixon et al. conferred a series filter operating as a curved current supply, that is a part of main voltage. The magnitude of the elemental ampere within the series filter is managed through the assistance of the false signal occuring among the load voltage and accomplished remark.

H. Hingorani et al. given the term custom power recommends that the usage of intensity physical science controllers for appropriation frameworks. The custom power will expand the standard and responsibleness of the capacity that is conveyed to the customers. Clients are the more and harder quality inside the power prepared by the electrical organization.

T.Devarajuet al. planned that power quality drawback is a happening manifested as a non-standard voltage, current or frequency that leads to a failure of types of equipment. Utility distribution networks, sensitive industrial hundreds, and important industrial operations all suffer from varied styles of outages and repair interruptions which might value significant loss per incident supported method downtime, lost production, idle workforces, and different factors. During this magnetism transient studies a drawn for the subsequent two ordinance power controllers: D-STATCOM and DVR workforces and different factors.

Olimpo Anaya-Lara et al. incontestible the modeling issue and analysis of ordinance power controllers a substitution generation of industrial electronics-based instrument line up toward increasing the responsibleness and nature of power flow into short tension distribution network. Graphics dependent structure appropriate for magnetism transient data are conferred for the subsequent 3 ordinance power controllers like the distribution static compensator (D- STATCOM), the dynamic voltage trained worker (DVR), and therefore the solid-state transfer switch (SSTS). Inclusive results are conferred to assess the achievement of every appliance as a possible ordinance power answer.

RVD Ram Rao et al. planned the standard of power is laid low with several factors like harmonic contamination thanks to non-linear hundreds, like giant thyristor power converters, rectifiers, voltage and current a flicker thanks to arc in arc furnaces, sag and swell thanks to the shift of the hundreds etc. One among the various solutions is that the use of a combined system of shunt and active series filters like (UPQC).

Malabika Basu et al. directed that Brought Unified Power Quality Conditioner (UPQC) is one among the most significant custom power arrangements that are fit for moderating the consequence of offer voltage sag at the load complete or the reason for common coupling (PCC). It moreover counteracts load current harmonics from getting into the utility and remedies the info power issue of the output.

Gu Jianjun et al. presented that the (UPQC), which goes for the blending of series dynamic(active) and shunt-dynamic power channels. the most reason for an UPQC is to make up for lost time with voltage irregularity, responsive power, negative-sequence current, and harmonics.

Ke Dai et al. conferred a three phase star or delta connection in series-shunt paid universal power quality conditioner supported 2 voltage-source converters controlled randomnly two digital signal processors. Completely differ from those in style active powers filters, voltage-source device in series is controlled as an advance curved current supply in part with the supply, whereas the shunt voltage supply device is managed as an elementary curved voltage source with const. voltage and const. frequency. 


\section{GUPQC TOPOLOGY}

\subsection{INTRODUCTION OF SVPWM}

These days, the vector measurement regulation system that is connected in AC-DC devices includes a huge amount of intriguing viewpoints. like adjustment of DC yield voltage, less harmonics in yield voltage and its higher power issue. These may encourage in supporting and up the capacity framework quality. This paper presents voltage the executives of such AC-DC devices utilized by the region vector pulse measurement adjustment.

SVPWM method and a one of a kind d-q casing approach. Hence, the device can redesign partner shaky information voltage from 3 segment AC framework into a steady DC yield voltage in exceedingly brief time reaction.

Space vector adjustment is a associative equation for the administration of vector pulse width regulation [1] it's utilized for the formation of electrical vitality (AC) waveforms; most ordinarily to drive 3 segment AC steam-power machines at variable velocities from DC exploitation different class$\mathrm{D}$ amplifiers. There are varieties of SVM that end in totally unique quality and procedure needs. One dynamic space of improvement is inside the decrease of all out symphonious mutilation made by the expedient change inborn to those calculations.

A 3-stage electrical converter as appeared to the right changes over a DC offer, by means of a progression of switches, to 3 yield legs that may be associated with a 3-phase machines.

The switches ought to be controlled all together that at no time are each switch inside a similar leg turned on as an option the DC offer would be shorted. This interest is additionally met by the correlative activity of the switches at interims a leg. For example in the event that $\mathrm{A}+$ is on, at that point $\mathrm{A}-$ is off and contrariwise. This outcomes in eight feasible switch vectors for the electrical converter, V0 through V7 with 6 dynamic switch vectors and 2 zero vectors.

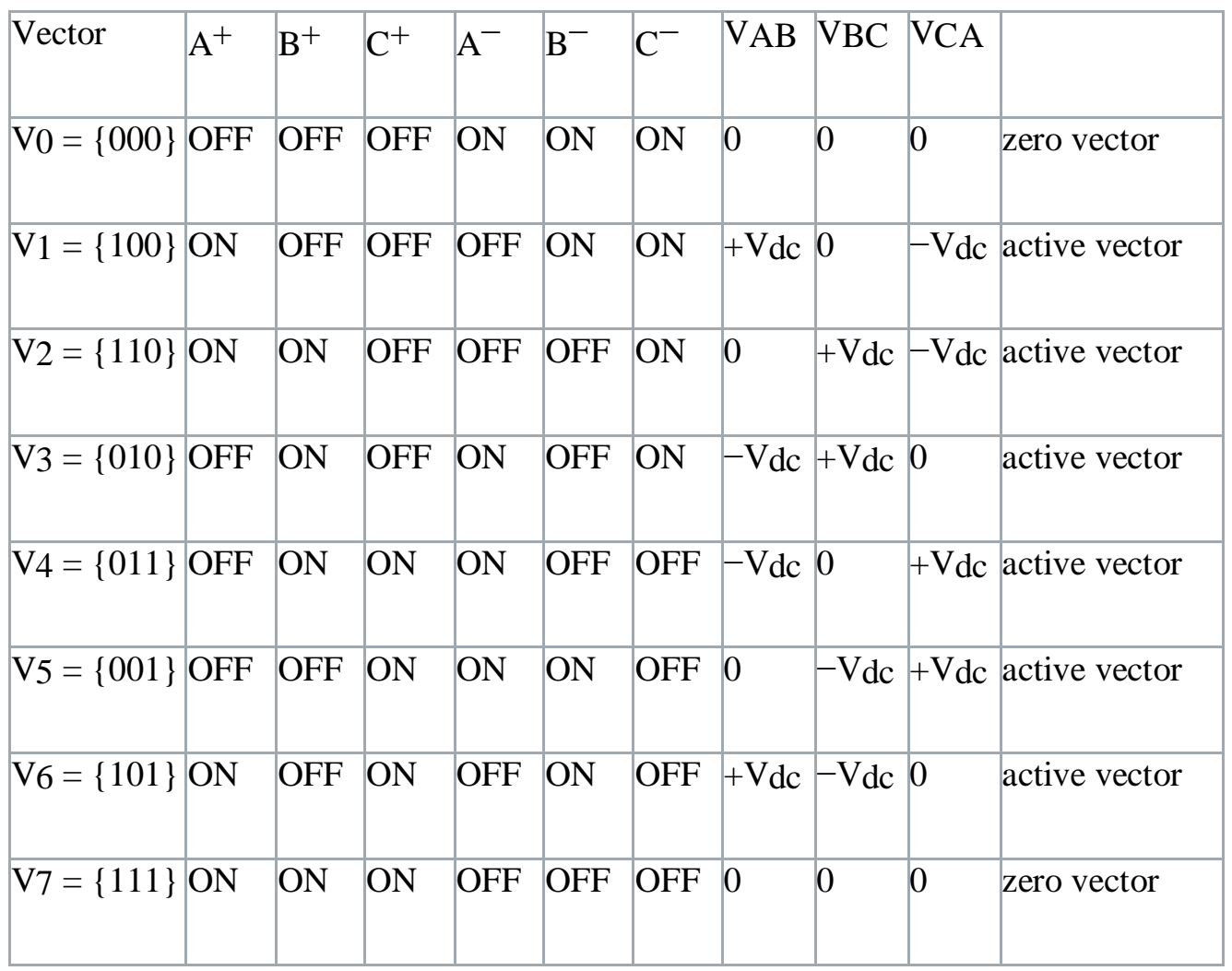


To execute territory vector tweak, a reference signal Vref is examined with a recurrence fs (Ts $=1 / \mathrm{fs}$ ). The reference sign is additionally created from 3 separate segment references exploitation the vogue (lalpha lbeta Igamma) redesign. The reference vector is then incorporated utilizing a blend of the 2 adjoining dynamic switch vectors and one or every one of the zero vectors. Various methods for picking the request for the vectors and that zero vector(s) to utilize exist. Methodology decision can affect the harmonics content and along these lines the switch losses.

Progressively refined SVM ways for the lopsided activity of 4-leg 3-stage inverters do exist. In these ways, the switch vectors layout a 3D structure (a polygonal shape crystal in lalphalbeta Igamma arranges [2] or a polyhedron in essentials organizes [3]) rather than a second polygonal shape.

Simulation model of region vector pulse measurement Regulation (SVPWM) Rectifier exploitation MATLAB/Simulink that capacity is to balance out associate yield voltage of $500 \mathrm{Vdc}$ from a 3 segment 300V framework utilizing a decoupling feed-forward administration method by d-q outline procedure. The model is tried due to a variety of $\pm 100 \%$ of the appraised info voltage. From the recreation model, it will use for execution into a tperiod of framework by Digital Sign procedure Board, (for example, DS1104). Together, it can likewise be planned into a genuine circuit just and successfully. The trial results demonstrate that the SVPWM Rectifier that is presented during this paper has a sufficient presentation which may be connected wide.

\subsection{Mathematical model of SVPWM AC-DC converter}

These days, the vector pulse measurement regulation strategy that is connected AC- DC gadget includes a huge amount of captivating angles. like adjustment of DC yield voltage, less sounds in yield voltage and its higher power issue. These may encourage in supporting and up the capacity framework quality. This paper presents voltage the board of such AC DC devices utilized by SVPWM method and an extraordinary d-q casing approach. Along these lines, the gadget can rebuild associate shaky information voltage from 3 area AC framework into steady DC yield voltage in exceedingly brief time reaction.

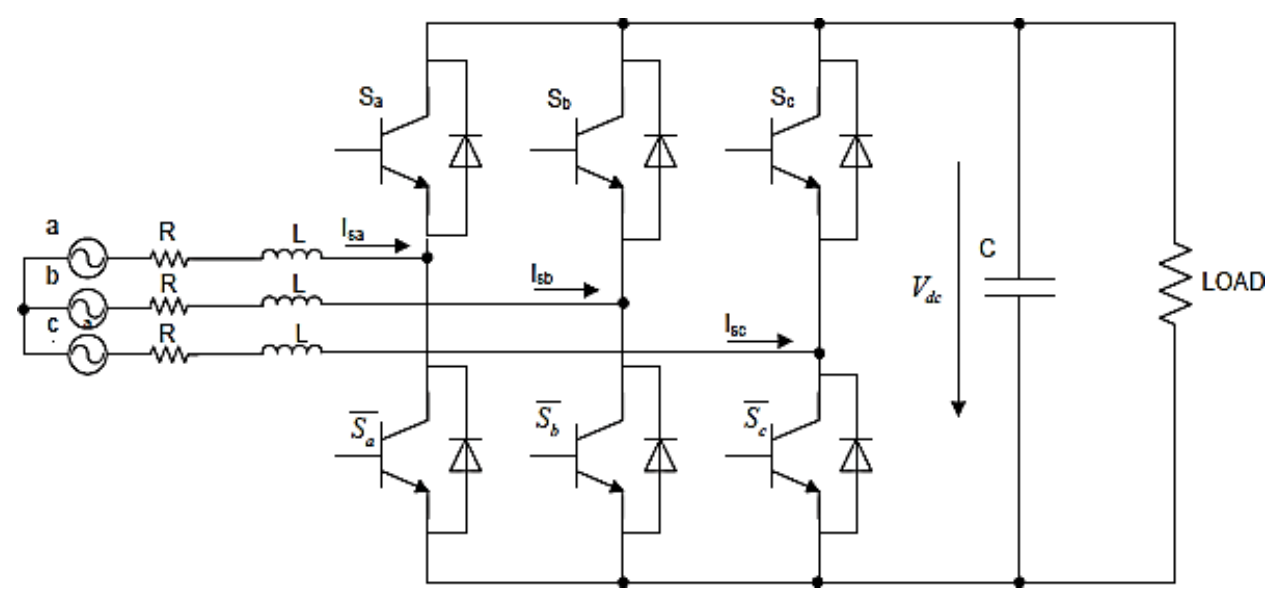

Figure 3.1.Mathematical model of SVPWM AC-DC converter circuit 


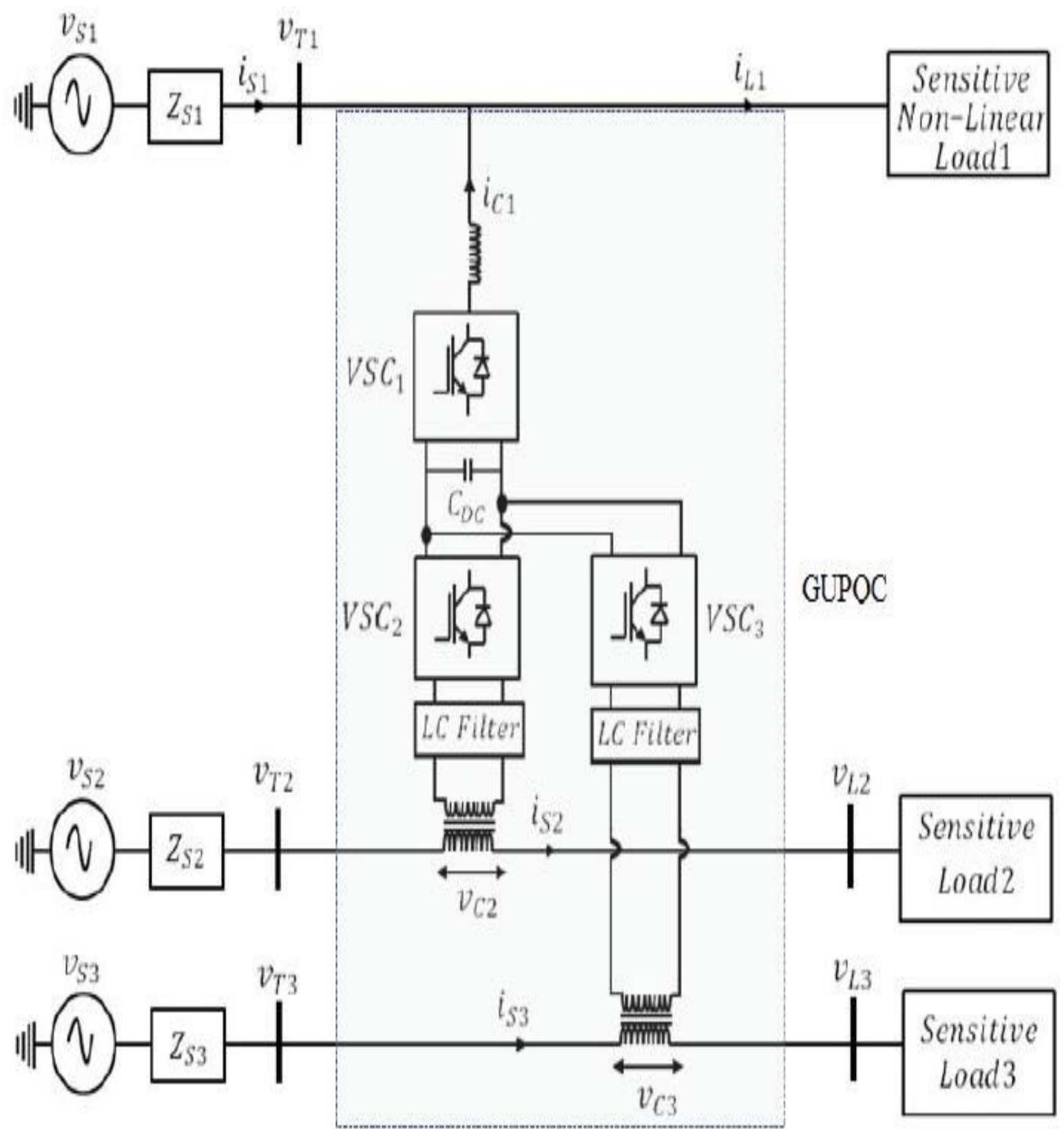

Figure 3.2. Typical model 


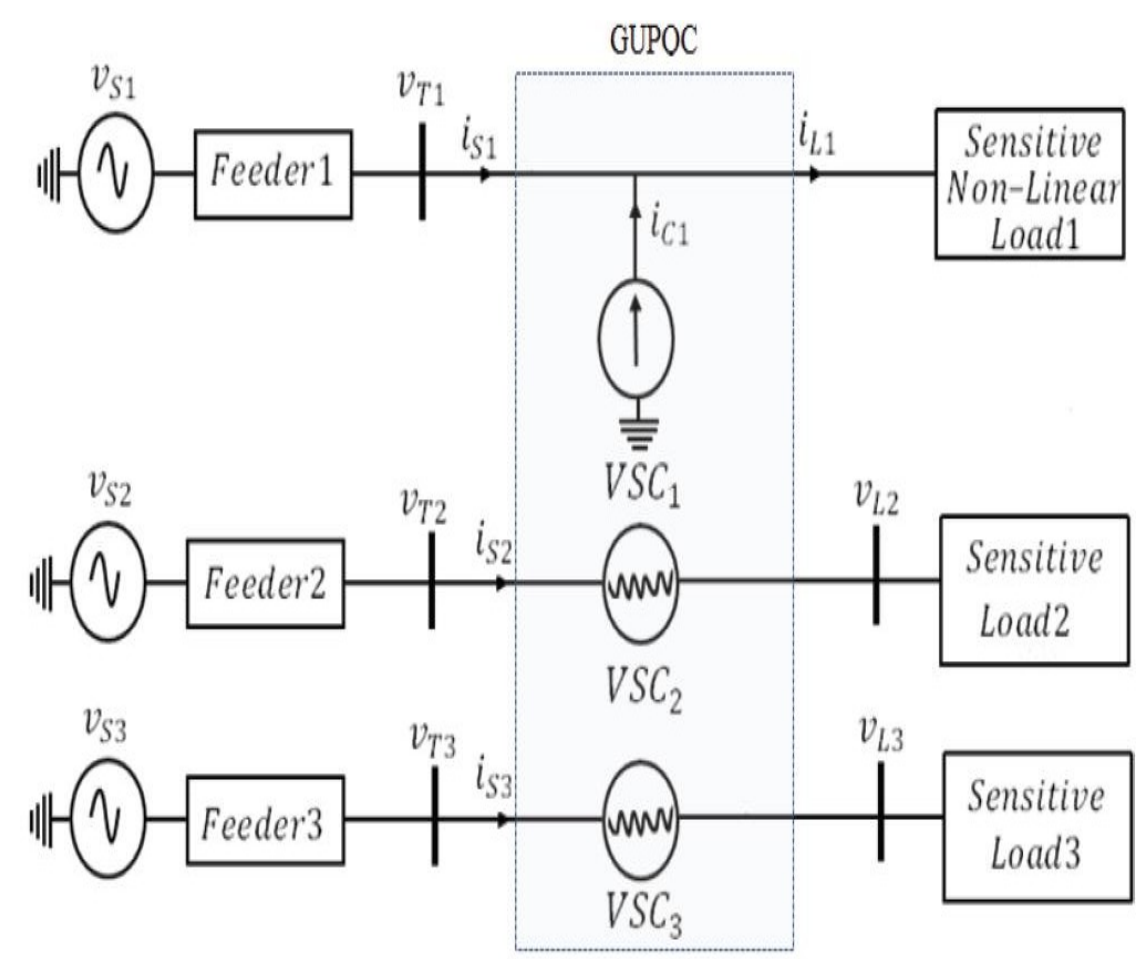

Equivalent circuit

Figure 3.3. GUPQC connected to multi-bus/3-feeder distribution system

\section{METHODOLOGY}

In this chapter, introduced a power flow analysis of the fundamental components of voltage and current, Furthermore, it introduced the control technique of GUPQC.

\subsection{Power Flow Analysis}

The power stream investigation was distributed underneath customary and exasperates states of the feeders upheld the essential components of voltage and current. Bolstered Figure 3.1(b) by considering the protection power issue masses on the feeders, the heap voltages and flows will be composed as appeared in (4.1) and (4.2) separately:

$$
\begin{aligned}
& v L n=V L n \angle 0^{\circ} \\
& i L n=I L n \angle-\varphi L n
\end{aligned}
$$

Here is the feeder index $n=1$, 2, or 3 . In expression of network voltage sag/swell etc., the supply voltage fluctuation factor, $x_{n}$ has been examine as (4.3). 


$$
x_{n}=\frac{V_{S n}-V_{i n}}{V_{L n}}
$$

So, supply voltage by the series compensators has to be examine as (4.4).

$$
V_{C n}=V_{L n}-V_{S n}=x_{n} V_{L n}<0^{\circ}
$$

Under deliberation of the without loss power of GUPQC networl, the active power suggested by the loads must be same as the active power given by the sources. So, the network active power is explained by taking equation (4.5):

$V_{S n} I_{S n}=V_{L n}\left(1+x_{n}\right) I_{S n}=V_{L n} I_{L n} \cos \varphi_{L n}$

Thus, the source current becomes:

$$
I_{S n}=\frac{I_{L n}}{\left(1+x_{n}\right)} \cos \varphi_{L n}
$$

From (4.6) bothI $\mathrm{Ln}_{\mathrm{Ln}}$ and $\varphi_{\mathrm{Ln}}$ are consistent for a specific sort of burden. Accordingly, the input current relies upon the input voltage variance factors. On the off chance that the input side voltage of feeder2 or feeder3 is exposed to the voltage hang/swell and so forth., the feeder1 supply current can be communicated as:

$$
I_{S 1}=\frac{I_{L 1}}{\left(1+x_{n}\right)} \cos \varphi_{L 1}-\frac{x_{2} V_{L 2} I_{L 2}}{\left(1+x_{2}\right) V_{L 1}} \cos \varphi_{L 2}-\frac{x_{3} V_{L 3} I_{L 3}}{\left(1+x_{2}\right) V_{L 1}} \cos \varphi_{L 3}
$$

The examine currentgiven by the shunt compensator which incorporates dynamic(active) and receptive(passive) current segments can be communicated by (4.8)

$I_{c 1}=I_{S 1}-I_{L 1} \angle-\varphi_{L 1}=\left(I_{S 1}-I_{L 1} \cos \varphi_{L 1}\right)+j\left(I_{L 1} \sin \varphi_{L 1}\right)$

So, shunt compensator is given following form of complex nature power:

$S_{V S C 1}=V_{L 1} I_{C 1}=V_{L 1}\left(I_{S 1}-I_{L 1} \cos \varphi_{L 1}\right)+j\left(V_{L 1} I_{L 1} \sin \varphi_{L 1}\right)$

$P_{V S C 1}=V_{L 1}\left(I_{S 1}-I_{L 1} \cos \varphi_{L 1}\right)$

$Q_{V S C 1}=V_{L 1} I_{L 1} \sin \varphi_{L 1}$

Feeder2 compensator, VSC2, active and reactive powers:

$P_{V S C 2}=-x_{2} V_{L 2} I_{L 2} \cos \varphi_{L 2}$

$Q_{V S C 2}=x_{2} V_{L 2} I_{L 2} \sin \varphi_{L 2}$

Feeder3 compensator, VSC3, active and reactive powers:

$P_{V S C 3}=-x_{3} V_{L 3} I_{L 3} \cos \varphi_{L 3}$

$Q_{V S C 3}=x_{3} V_{L 3} I_{L 3} \sin \varphi_{L 3}$

In view of the above dynamic(active) and responsive(passive) power conditions, the power stream in the 3 feeders an investigation was completed in the accompanying contextual analyses to demonstrate the capacity of the GUPQC to keeping up the general power balance into a multi/ 3-feeder distribution 
framework.

\section{RESULT ANALYSIS}

\subsection{Simulation tool and Software}

So as to assert the general execution and the viability of the proposed series compensator controller adjacent to the electricity float with the GUPQC a broad recreations information have been achieve with the assistance of MATLAB /SIMULINK.

\subsection{Result and Analysis}

The recreation model of GUPQC test block in MATLAB/SIMULINK stage is represented as in Figure 5.1.

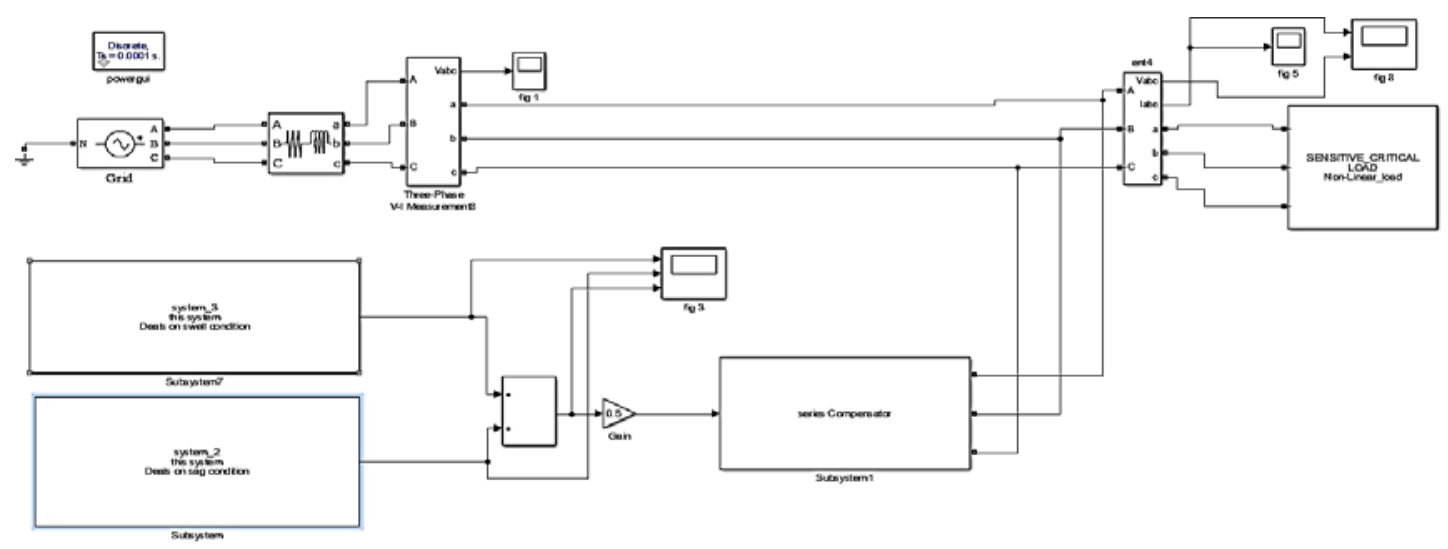

Figure 5.1. Simulation model of GUPQC system in MATLAB/SIMULINK platform

CIRCUIT OF SPACE VECTOR

PULSE WIDTH MODULATION

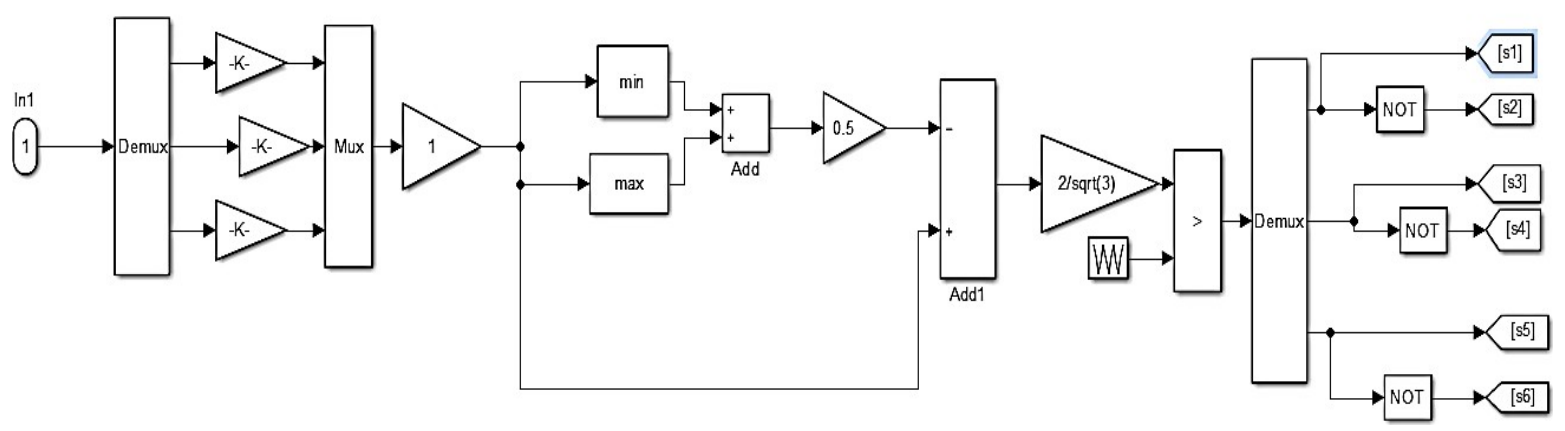




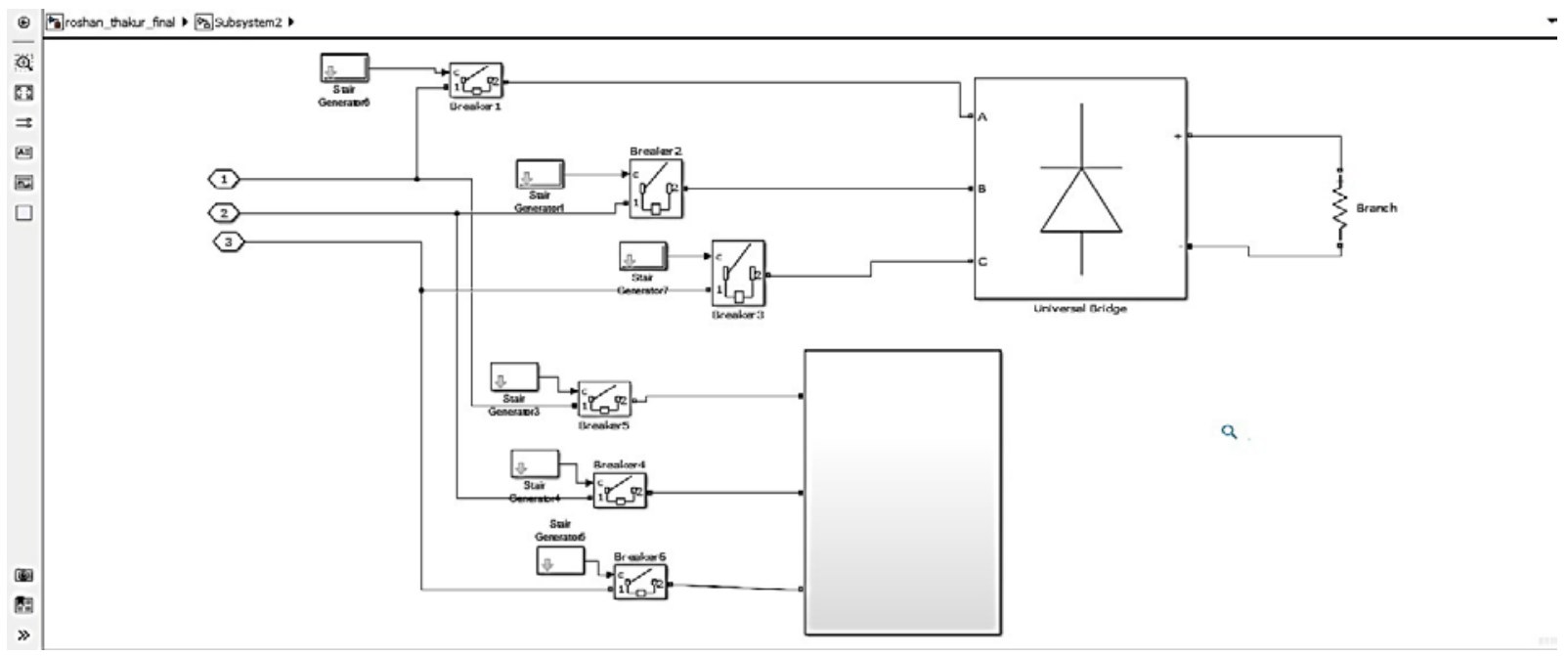

Figure 5.2Simulation model of SVPWM \&Sensitive Critical Load system in MATLAB/SIMULINK platform

As the we seeen the initially the linear part was related with the system and sensitive or fragile load1 is a blend of linear and non-linear stacks. At $\mathrm{t} 1=0.10 \mathrm{~s}$, shunt compensator was set into the action as found in Figure 5.3 and rapidly started injecting the compensation current, i.e., non-dynamic current portion. At $\mathrm{t} 2=0.15 \mathrm{~s}$, to compensate for current distortion, the non-linear bit of the fragile nonlinear load1 was relatd.
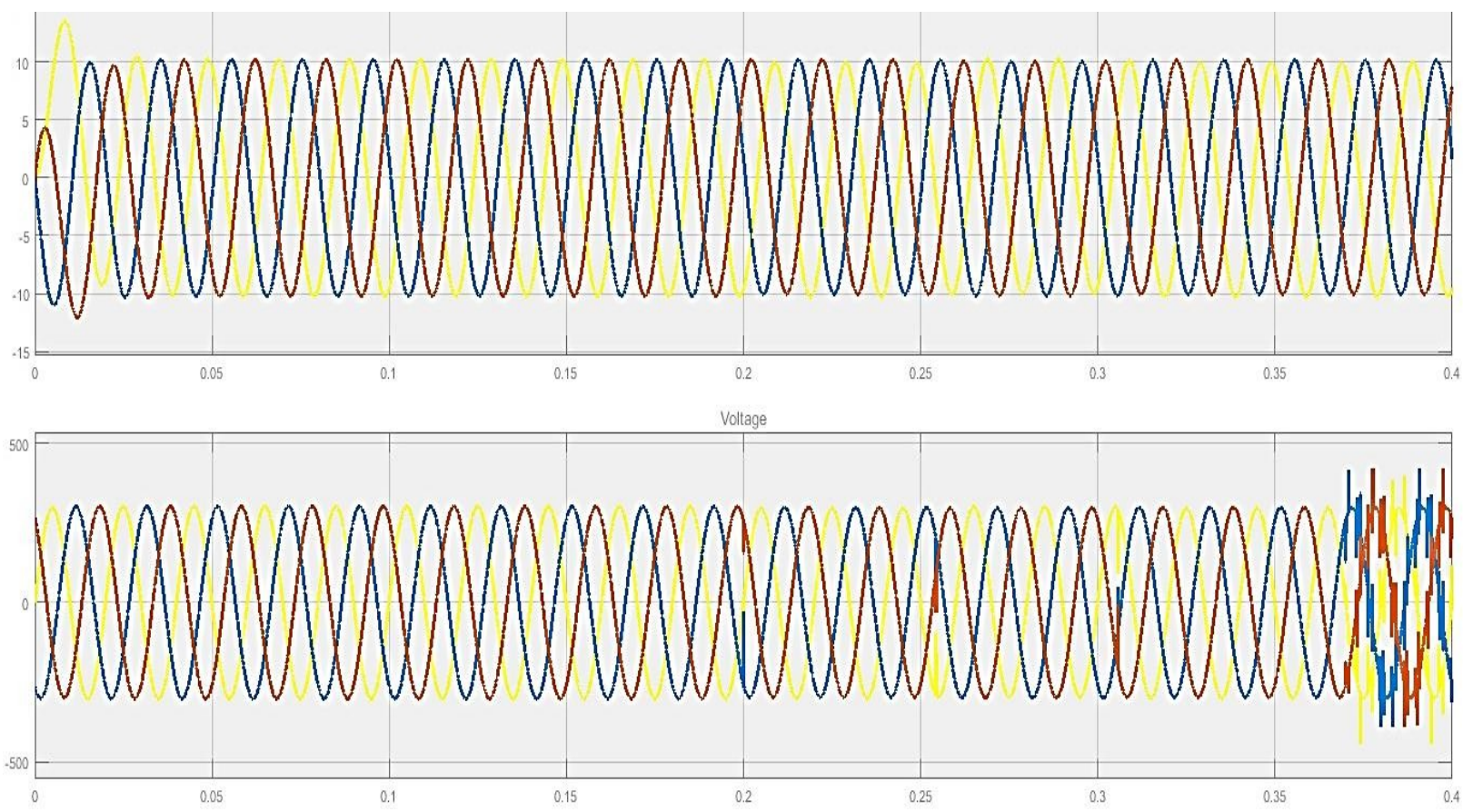

Figure 5.3.A Final source voltage, source side current andcompensation current 

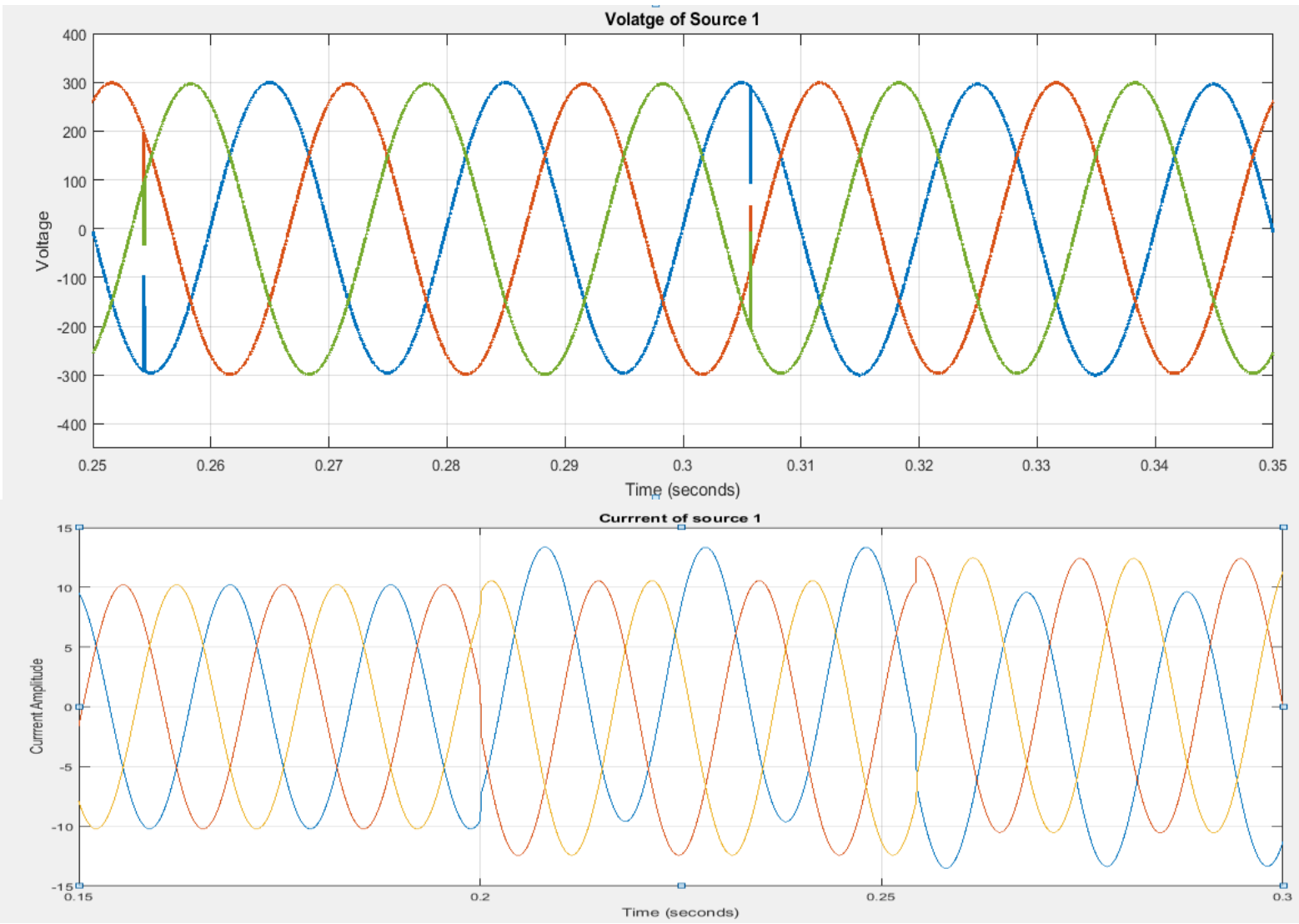

Figure 5.3.B. source voltage, source side current

The contortion of the supply voltages other than the voltage list/swell was repaid with great repaying attributes of the GUPQC dependent on the proportinal controller. The reaction of the shunt compensator to the adjustments in the framework voltages (control stream) was displayed as in Figure 5.4 as far as the supply area current of feeder 1 and DC-interface capacitor voltage. 

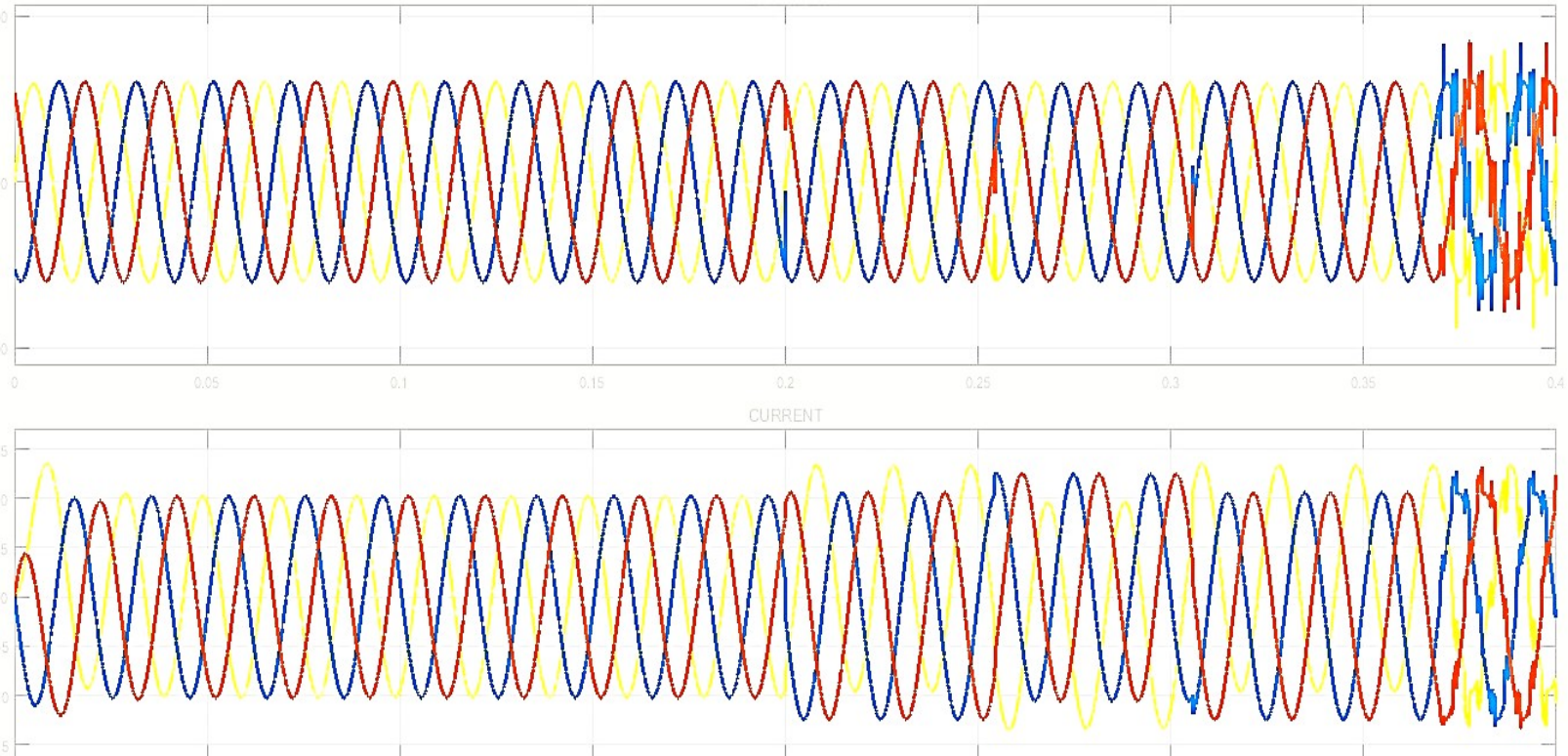

Figure 5.4.A Source voltage, source side current and compensationcurrent withoutany condition

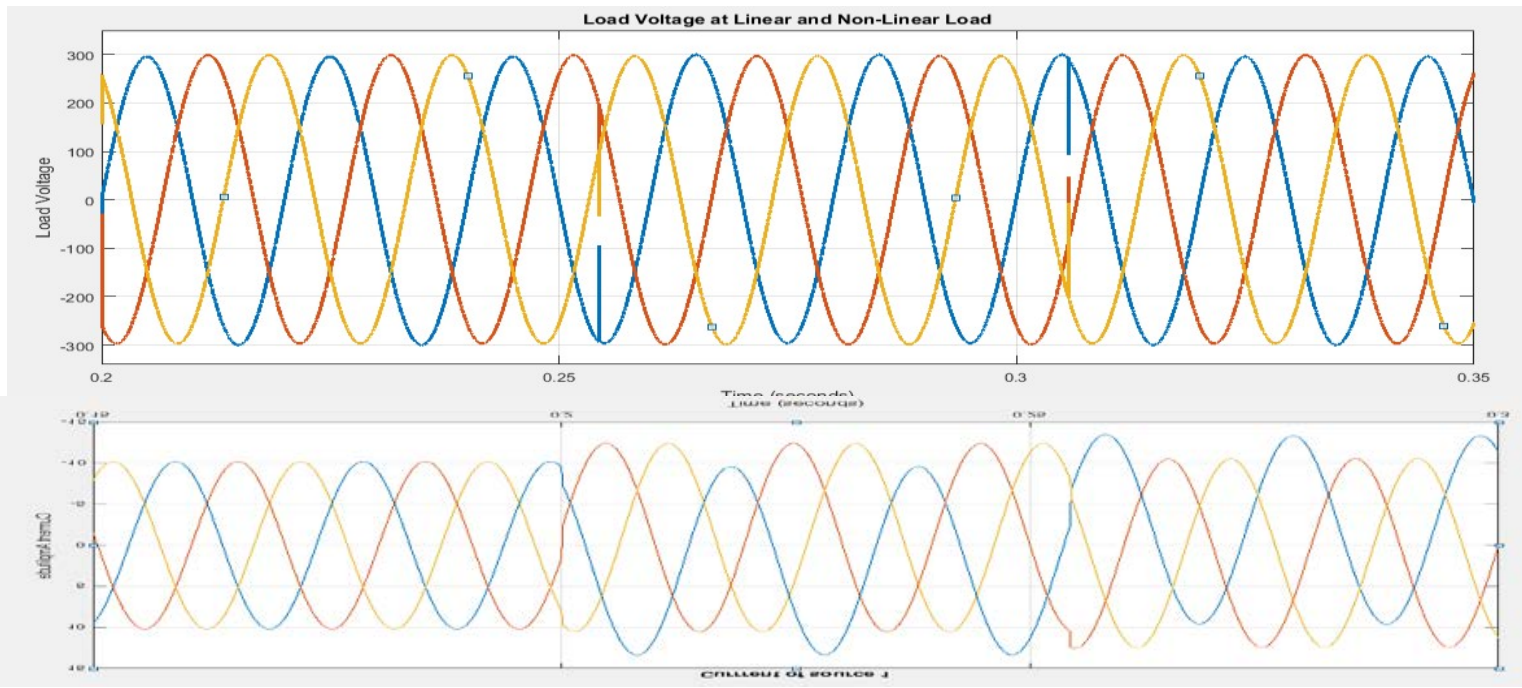

Figure 5.4.B Source voltage, source side current and compensation current without any condition 


\section{CONCLUSIONS}

In this work, the power stream investigation through the GUPQC associated with the multi- bus/3feeder circulation frameworks was completed. Another controller conspires for the series compensator of GUPQC dependent on the d-q hypothesis to make up for the supply or given side voltage disruption (harmonics), voltage droop/swell and intrusion was introduced. The use of the defined controller to make up for voltage defects of the system and for the improvement of the power nature of the client burdens was approved by the simulation results. It has additionally been shown that the parallel compensator dependent on the created controller successfully kept up the power adjusted next to the DC-interface capacitor at the ideal level.

\section{REFERENCES}

[1] El Mofty and K. Youssef, "Industrial Power Quality Problems", Conference onElectrical Distribution, vol.2,pp. 18-21, June 2001.[10]

[2] Mokhtatpour and H.A. Shayanfar "Power Quality Compensation as Well as Power Flow Control Using of Unified Power Quality Conditioner”, Asia-Pacific Power and Energy Engineering Conference (APPEEC), Page(s): 1 -4, 2011. 31

[3] A.K. Jindal A. Ghosh, and A. Joshi, "Interline unified power quality conditioner," IEEE Trans. Power Delivery, vol. 22, pp. 364-372, 2007.[6]

[4] Ahmed M. A. Haidar, Chellali B enachaiba, Faisal A. F. Ibrahim andKamarulHawari“Parameters Evaluation of Unified Power Quality Conditioner”,IEEE International Conference on Electro/Information Technology (EIT), page(s):1-6, 201125

[5] ArindamGhosh and Gerard ledwhich, "Power Quality Enhancement Using Custom Power Devices”, Kluwer Academic Publishers, 2002. [15]

[6] ArindamGhosh andAmit Kumar Jindal, “A Unified Power Quality Conditioner forVoltage Regulation of Critical Load Bus”, IEEE Conference on Power Delivery Transactions Vol. 22, page(s): $364-372,2007.28$

[7] Han, B. Bae, S. Baek and G. Jang, "New configuration of UPQC for medium-voltage application,’IEEE Trans. Power Delivery, vol. 21, no. 3, pp. 1438- 1444, Jul. 2006.[2]

[8] B.E.S. Mohammed, K.S. Rama Rao and N. Perumal"Improvement of power quality of a two feeder system using unified power quality conditioner," in Proceedings of IEEE National postgraduate. Conference (NPC), Dec. 2011.[8]

[9] D.G. Flinn, C. Gilker and S.R. Mendis, "Methods for Identifying Potential PowerQuality Problem”, Conference on Rural Electric Power, February 3, 1991.[12]

[10] F. Z. Peng, L. M. Tolbert and Z. Qian, "Definitions and compensation of non-active current in power systems” in Proceedings of 33rd IEEE Annual Power Elect. Special Conf., pp. 17791784, 2002. 39 